\title{
IDENTIFICATION OF TECHNOLOGY INTEGRATION CHALLENGES AT TWO GLOBAL AUTOMOTIVE OEMS
}

\author{
I. Alonso Fernández ${ }^{凶}$, M. Panarotto and O. Isaksson \\ Chalmers University of Technology, Sweden \\ $\triangle$ inigo.alonso@chalmers.se
}

\begin{abstract}
Platform design has been firmly established in the automotive industry as a strategy to provide wider product variety while maintaining cost effective production. But this strategy can struggle to keep up with the pace and nature of emerging technologies. This paper reviews the existing approaches to modelling product platforms, and showcases the challenges at OEMs introducing new technological innovations in their platforms. A gap is identified in the methods to assess the ability of existing platforms to integrate new technologies whenever they become available.
\end{abstract}

Keywords: product platform, technology development, product architecture, decision making, innovation

\section{Introduction}

The automotive industry is a highly competitive, low-margin industry, and manufacturers face an ever-increasing pressure to maintain the margin between their revenues and costs. For years, the industry has developed strategies and organisations that maximise the diversity of their offerings to meet individual customer's needs in a global market, while keeping the cost of realization minimal.

A car, nowadays consisting of tens of thousands of components, or a truck, theoretically allowing up to $10^{200}$ individual combination opportunities (Schroeder et al., 2016), demand clear strategies for balancing the number of allowable set of variants to be produced to be able to cope with the combinatorial explosion of possibilities. One of these strategies is the use of product platforms (Jiao et al., 2007), where most car manufacturers and truck manufacturers have established their own ways of defining a platform.

This work presents an in-depth study of two use cases on the present challenges perceived inside the development organisation at two automotive Original Equipment Manufacturers (OEMs) (Volvo Car Group, VCG, and Volvo Group Truck Technology, VGTT), when assessing and evaluating how to integrate next generation technologies in their existing platforms.
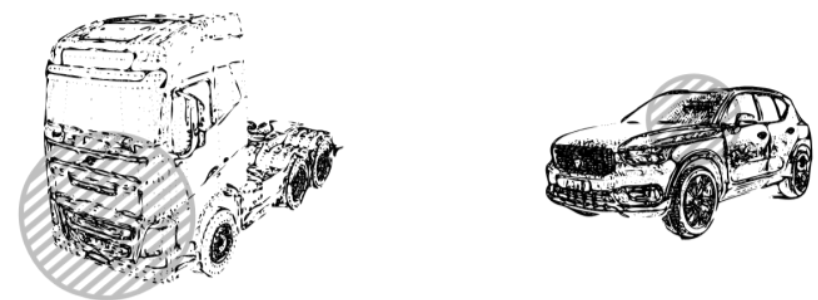

Figure 1. Industrial cases from VGTT (left) and VCG (right) 
VCG manufactures and markets luxury cars, and VGTT participates in the development of trucks distributed in more than 190 markets world-wide by different brands (e.g. Volvo Trucks, Renault Trucks, Mack, UD Trucks). The current use case explored with VCG was a digital information display system, and in the case of VGTT a cabin subsystem, including environment sensors.

Several variants of a certain vehicle are based on the same platform, and often this platform is expected to last for up to a decade to recover the $\mathrm{R} \& \mathrm{D}$ cost incurred in its development.

At the same time, there are several radical technological transformations underway, including the introduction of increasingly autonomous vehicles, the replacement of conventional internal combustion powertrains with electrical, hybrid or hydrogen powered alternatives, and the shift into digital solutions that replace classical, mechanical or electro-mechanical, functions in the vehicles. Also, materials, manufacturing methods, and assembly processes are experiencing radical changes. In many cases, the platform architecture and its interfaces are challenged, and important questions arise.

- What challenges are encountered at automotive manufacturers when trying to generate value by integrating new technologies into established product platforms?

Platform based development by enforcement of compliance with an existing structure (architecture) in the automotive sector, may limit innovation and the adoption of new emerging technologies. Unless the consequence and impact on the existing platform of a new technology can be clarified and understood, the risk of introducing such technology may remain too high. The phase of the design process where technology integration options are considered, elaborated and judged needs to be aptly supported.

\subsection{Context and gaps}

Meyer and Lehnerd (1997) define a product platform as 'a set of subsystems and interfaces that form a common structure from which a stream of derivative products can be efficiently developed and produced'. A technology is defined as the body of knowledge the design, development and manufacture of the product relies on (Brusoni et al., 2001).

Products are becoming increasingly multi-technological (Patel and Pavitt, 1997), relying on specific but different technologies to fulfil their functions and to be manufactured. The behaviour of the product as a system is largely determined by the combined characteristics governed by the constituent components and their interrelations. Integrating new technologies as they reach a certain maturity status is thus becoming a more pressing decision.

The product development cycles in the automotive industry are driven by a market demanding new models on a more frequent basis (market pull), and the parallel development of new technologies (technology push) that are rapidly demanded and expected by the customers, e.g. in the ICT sector. Automotive OEMs offer fundamentally standardized products, which makes them try to differentiate their brands by offering a wide diversity of options and upgrades to their base models. Additionally, more and more restrictive environmental regulations are also forcing OEMs to have to adapt and evolve their products. The introduction of architectural frameworks in the context of software and electronics has been described (Eklund et al., 2005), as well as the challenges of software architecting in the automotive domain (Eliasson et al., 2015). The use of standardized layouts to support variant management in the automotive sector was proposed by Förg et al. (2014) and Stocker et al. (2016).

Big groups of multidisciplinary experts are tasked with fulfilling some dynamic business goals by coordinating their efforts and making the best decisions with the information available. The expected rate of launching new models and variants in combination with ever increasing variety of technologies to integrate (e.g. electronics, software, new materials...) create a true challenge for early phase design. This difficulty to integrate new technologies to expand a product family has been brought up in the literature (Halman et al., 2003).

Based on these considerations, this work reports on the challenges encountered when introducing a new technology into a product derived from a platform, and it advances our understanding of the current practice. This study contributes to the description of the "as is" status of industrial practice and the analysis of the current challenges and trends. It also provides an initial contribution to an 
upcoming prescriptive study, proposing the introduction of a model-based method to support early decision making in the platform development process.

\section{Method}

The study fulfils the role of a Research Clarification (RC) study within the Design Research Methodology (DRM) framework (Blessing and Chakrabarti, 2009). It combines a review of the literature with an empirical study, using industrial use cases from two OEMs (VGTT and VCG).

The literature review process was iterative and was composed of the generic activities of formulating the research question, searching the extant literature, screening for inclusion, assessing the quality of the results, extracting data and analysing data (Templier and Paré, 2015). Some of these activities were launched in the planning stages of the study and all of them were refined in later phases.

In the industrial use cases, a total of twenty-eight participants from the two OEMs, with an average experience in the automotive industry of 17.32 years $(\mathrm{SD}=8.3)$ and spanning across all the disciplines involved in the development of a new product were involved. The roles of the participants are listed in Table 1 . They were proposed by each of the internal functions of the companies.

Table 1. Roles of participants

\begin{tabular}{ll}
\hline VGTT & VCG \\
\hline VP Technology Cab & Product Owner \\
Global Platform Manager & Lead Engineer \\
Group Manager & Portfolio Manager \\
CAB Engineering Task Leader & UX Architect \\
Lead Engineer & Attribute Leader Ergonomics \\
Product Development & Attribute Leader Service \\
Cab Platform Architect & Attribute Leader Safety \\
Product Planning & Principal Engineer Solidity \\
Active Safety & Expert Studio Engineer \\
Climate System & Cockpit Integration \\
Passive Safety Technology Specialist & Mechanical Integration \\
Crash and Safety Simulation Engineer & Manufacturing Engineer \\
GTM Cab Exterior & System Manufacturing Engineer \\
Technical Specialist Physical Ergonomics & \\
Front Underrun Protection & \\
\hline
\end{tabular}

The use cases were selected in collaboration with the manufacturers, aiming for systems with interfaces to many different stakeholders. To guide both the workshops and interviews, a questionnaire was used. The questionnaire was divided in two parts, the first focusing on the experience of the participants in previous introductions of a new technology, and the second focused on the current challenges with the selected use case. The questions, summarized in 0, were accompanied by brief explanations and examples, and were answered in free form text format.

Table 2. Summary of questionnaire

\begin{tabular}{l}
\hline First part \\
\hline Identify some situation in the past where the integration of a new technology caused some issues \\
What were the consequences of not being able to solve these issues? \\
What engineering aspects impacted these issues? \\
\hline Second part \\
Identify your expectations regarding the integration of [the current use case] \\
What would be the consequences if those expectations are not met? \\
What engineering aspects will impact these expectations?
\end{tabular}


The procedure followed during the workshops was to first reflect on previous experiences, and then to discuss with the rest of the group the experiences of each of the individuals and add or refine the answers to the questionnaire. Using groups enables a more varied elicitation plus it allows for management to observe (Ulrich and Eppinger, 2012). The second part involved reflecting on the current issues being encountered and recording everyone's expectations regarding the use case. Finally, the use case and the expectations of all the stakeholders were discussed in the group, and the questionnaire was finalized with any additional insight. Two individual interviews were held following an equivalent semi-structured procedure, to ensure all disciplines with a stake in the project (as judged by the project leaders) were represented in the dataset, and to avoid relying on opportunistic inputs.

The workshops took around three hours to complete each, and the semi-structured individual interviews around one hour each. The analysis of the data was carried out in two stages. During the pre-processing stage, the answers were transcribed from the hand-written questionnaires into a spreadsheet, cleaned typos and spelling mistakes, expanded acronyms, and verified the cleaned-up dataset with the stakeholders. The main analysis consisted in the categorization of data, by coding the drivers of change, constraints and challenges discussed by the participants.

Relying solely on interviews can limit the completeness of the dataset. A more complete dataset may be obtained by observing model use in the design process with observations and ethnography methods. Observation is however extremely demanding of research resources when decision processes span a long-time period (Mintzberg et al., 1976). Therefore, we were obliged to rely heavily on interviews.

Furthermore, tapping the memories of decision-makers can introduce errors of memory failure, as well as a risk of 'recall vs. reality' where people often overly rationalise their own viewpoints. These limitations were approached by asking the interviewees beforehand to relate as much as possible of their last completed project so that these situations remained fresh in their minds.

\section{Results}

\subsection{Literature review}

The literature around product platforms is abundant. The state of the art on product platform design methods and tools was summarized by Jiao et al. (2007).

The design method used to develop a new product can have a big impact on the possibilities of the manufacturer to adopt a platform strategy. Some design methods might be better suited than others to this task, and some are even geared towards that goal explicitly. Different product platform design approaches (top-down/business oriented, bottom-up/technically oriented), have been proposed, for example (Johannesson et al., 2017) explore the use to an approach based on object orientation and function modelling. The use of modularity for platform design was discussed by Hölttä-Otto (2005).

Modelling approaches can vary depending on the design method used, for example the Modular Function Deployment (MFD) method (Erixon, 1998) focused on the creation of modular architectures. Design space exploration methods like Multi-Attribute Tradespace Exploration (MATE) (Ross et al., 2004) provide a way to propagate an utility function throughout different levels of design. The Flexible Product Platform Development process proposed by Suh et al. (2007) dealt with component decomposition. Multidisciplinary approaches like Set-Based Concurrent Engineering (SBCE) use models that integrate functions and components (Levandowski et al., 2014), focusing on the allocation of system function to physical elements. The Value-Driven Design (VDD) methodology (Isaksson et al., 2013), combined with the Concept Design Analysis (CODA) method (Woolley et al., 2001), attempts to strengthen the requirements establishing process, iterating at different levels.

The architecture, or internal structure, of the product platform has been modelled in several ways, like the Generic Product Modelling (GPM) (Erens and Wortman, 1996), the Generic Variety Structure (GVS) and Product Family Architecture (PFA) (Jiao and Tseng, 1999), the Generic Bill-Of-Materials (GBOM) (Jianxin Jiao et al., 2000), the Generic Product Structure (GPS) (Du et al., 2003b), Graph Grammars (Du et al., 2003a), and Module-Interface Graphs (Otto et al., 2016). 
The interrelations between product structures and their effects has been modelled (Hackl and Krause, 2017), showing which effects are most likely occur when a certain modular product structure is used, and how this choice affects other phases of the product lifecycle.

Many metrics have been defined to grade product platforms and mass customization, including modularity, scalability, and commonality of components. As the cost is the most intuitively understood metric for any business endeavour, methods like the Product Architecture Assessment have been widely used in business management contexts for product architecture costing (Fixson, 2006). Two main variables studied in the literature are the commonality cost reductions (Thyssen et al., 2006; Farrell and Simpson, 2010), and the product technical performance (i.e. product quality, product effectiveness). The use of product platforms was linked to the creation of value (Meyer and Lehnerd, 1997), and the existing research on the analysis of value during product development and value-driven design was captured by Isaksson et al. (2013) for the aerospace industry.

How easy it is for that basis to be reused and repurposed can be described as the "flexibility" of the platform, following definition of flexibility: "the ability to change or adapt with little penalty in time, cost, effort or performance" (Upton, 1994). Analysis of flexibility has been approached from many perspectives like from the management side by (Jana et al., 2018), or from a change viewpoint (Bauer et al., 2015). Other investigations in to the behaviour of systems exposed to change and the propagation of its effects has led to the development of mathematical models to predict the risk of the change (Clarkson et al., 2004). Haubelt et al. (2002) introduced a hierarchical graph model to formally model the flexibility and cost of a system. The AMISA project aimed to optimize systems' architectures towards maximum lifecycle value by developing a quantification methodology for Design for Adaptability approaches (Schrieverhoff et al., 2012).

Two critical aspects of flexibility have been defined (Buganza and Verganti, 2006): the product flexibility and the development process flexibility. Both the strategic decision-making process that enables product flexibility and the product development process are intimately interwoven, and their common interfaces define the bulk of product flexibility. A lot of the recent research has been focused on the flexibility that electronic systems and software can enable in the automotive industry, and the current use of electronic and software architectures (Pelliccione et al., 2017).

Kim and Moon (2017) described "high sustainability, low risk to product redesign, and high commonality" as the three characteristics of a sustainable platform. Balancing the trade-off between economic efficiency of platforms versus platform effectiveness (Agard and Bassetto, 2013), and the number of product platforms based on that trade-off (De Weck et al., 2003) (Seepersad et al., 2000) has been extensively considered. Mirshekarian (2015), expanded the Time-Expanded Decision Networks framework proposed by Silver and de Weck (2007), addressing the evolvability problem (among other ilities, as described by De Weck et al., 2012).

The modelling of the product platform evolution and its lifecycle has been approached by using methods like the Architecture Roadmap, a close relative of the higher-level Technology Roadmap. More analytical methods exist, like the Epoch Syncopation Framework (ESF) (Fulcoly et al., 2012). At automotive OEMs, scoring and achievement charts/spreadsheets traditionally guide business decisions.

Multidisciplinary and multi-technological approaches, like a development architecture (DA) have been postulated (Oh et al., 2019) to link market, design, and production structures. The analysis and improvement of engineering design processes themselves in the automotive sector has also been described using complexity metrics (Kreimeyer and Lindemann, 2011).

The number of product platforms and their "under- or overdesign" (contrasted with the products derived from them) in a firm have been proposed as drivers of the trade-off between the cost of the platforms and the cost of deriving products from a customizable platform (Van Den Broeke et al., 2015).

However, there is still an open question regarding how to support decision making when introducing new technologies that risk intruding upon the existing platforms, so that their impact and value adding projections can be assessed early enough to make a difference.

\subsection{Industrial use cases}

A summary of the data gathered at VCG and VGTT is presented in Table 3, for the drivers of change (the introduction of a new technology), and the constraints (boundaries for the development teams 
efforts) encountered during the current use cases and the previous individual experiences of the participants.

Table 3. Change drivers and constraints in automotive use cases

\begin{tabular}{|c|c|c|c|c|}
\hline & \multicolumn{4}{|c|}{ Use cases } \\
\hline & \multicolumn{2}{|c|}{ VGTT } & \multicolumn{2}{|c|}{ VCG } \\
\hline & $\begin{array}{l}0 \\
0 \\
0 \\
0 \\
0 \\
0\end{array}$ & $\begin{array}{l}\overrightarrow{0} \\
\stackrel{0}{0}\end{array}$ & $\begin{array}{l}0 \\
\frac{0}{2} \\
\vdots \\
0\end{array}$ & 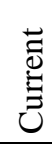 \\
\hline \multicolumn{5}{|l|}{ Change drivers } \\
\hline \multicolumn{5}{|l|}{ External changes } \\
\hline Legislation and regulations & $\bullet$ & $\bullet$ & $\bullet$ & $\circ$ \\
\hline Customer preferences & $\bullet$ & $\bullet$ & $\bullet$ & $\bullet$ \\
\hline \multicolumn{5}{|l|}{ Internal changes } \\
\hline Portfolio planning & ○ & $\bullet$ & ○ & $\bullet$ \\
\hline Services (car sharing, leasing...) & ○ & ○ & $\bullet$ & $\circ$ \\
\hline \multicolumn{5}{|l|}{ Technological development } \\
\hline Mature technology & $\bullet$ & ○ & ○ & $\bullet$ \\
\hline Autonomous driving & $\bullet$ & $\bullet$ & ○ & $\circ$ \\
\hline Powertrain electrification & $\circ$ & $\bullet$ & $\bullet$ & $\bullet$ \\
\hline \multicolumn{5}{|l|}{ Constraints } \\
\hline \multicolumn{5}{|l|}{ Time } \\
\hline Time to market & ○ & $\bullet$ & ○ & $\circ$ \\
\hline \multicolumn{5}{|l|}{ Assets and costs } \\
\hline Development costs & $\bullet$ & $\bullet$ & ○ & $\circ$ \\
\hline Existing production processes & $\bullet$ & $\bullet$ & $\bullet$ & $\circ$ \\
\hline Existing components & $\bullet$ & $\bullet$ & $\bullet$ & $\bullet$ \\
\hline \multicolumn{5}{|l|}{ Regulations } \\
\hline Environmental & $\bullet$ & $\bullet$ & $\bullet$ & $\circ$ \\
\hline Safety & $\bullet$ & $\bullet$ & $\bullet$ & $\bullet$ \\
\hline \multicolumn{5}{|l|}{ Organization } \\
\hline Culture and values & $\bullet$ & $\bullet$ & ० & $\circ$ \\
\hline Multi-site teams & ○ & $\bullet$ & ० & $\circ$ \\
\hline Competencies & $\bullet$ & $\circ$ & $\bullet$ & $\bullet$ \\
\hline
\end{tabular}

- Present, $\circ$ Not discussed

Compared to 0 , results in 0 show more specific challenges encountered by the development teams in their decision making contexts, and as such reflect better the internal discussions observed in the teams. The challenges present at each firm are compared with the existing literature regarding the obstacles to the introduction of new technologies in product platforms. Similitudes between both cases highlight the commonalities in practice are very strong in the automotive sector, and more so for companies that share the same talent pool for their recruiting.

The issues mentioned most often were related to the integration of existing components and production processes, interface management, regulatory compliance and market trends. The most significant differences were related to the different disciplines involved in the use cases discussed, and their direct impact on the user experience.

The findings from the use case discussions show that the drivers for change as well as high level constraints also reported in literature are evident in the cases studies. More interestingly, several additional challenges were revealed, highlighting that there are several decision-impacting factors that 
are less well understood. Together, the multi-disciplinary nature of such issues is one of the main reasons why the prevalent means to deal with these are man power intensive (i.e. meetings, issue escalation).

Table 4. Challenges in the introduction of new technologies

\begin{tabular}{|c|c|c|c|c|c|}
\hline & \multicolumn{4}{|c|}{ Use cases } & \multirow[b]{3}{*}{ } \\
\hline & \multicolumn{2}{|c|}{ VGTT } & \multicolumn{2}{|c|}{ VCG } & \\
\hline & 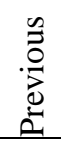 & 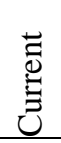 & 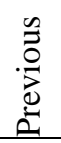 & $\underset{\Xi}{\overrightarrow{0}}$ & \\
\hline \multicolumn{6}{|l|}{ Challenges } \\
\hline Uncertainty management & $\bullet$ & $\bullet$ & o & o & $\bullet^{\mathrm{a}}$ \\
\hline Development lead time & o & o & o & $\bullet$ & $\mathrm{a}^{\mathrm{b}}$ \\
\hline Meet environmental regulations & o & $\bullet$ & ○ & ○ & $\bullet^{c}$ \\
\hline Technology maturity & $\bullet$ & $\bullet$ & ० & • & $\bullet^{\mathrm{d}}$ \\
\hline Customer satisfaction & $\bullet$ & o & $\bullet$ & $\bullet$ & $\mathrm{\sigma}^{\mathrm{e}}$ \\
\hline Interface management & $\bullet$ & $\bullet$ & $\bullet$ & $\bullet$ & $\mathrm{a}^{\mathrm{b}}$ \\
\hline Impact on after-sales service & ○ & $\bullet$ & $\bullet$ & $\bullet$ & $\circ$ \\
\hline Availability, reliability, durability & ० & $\bullet$ & $\bullet$ & $\bullet$ & ○ \\
\hline Resistance to change & $\bullet$ & $\bullet$ & ○ & $\bullet$ & ○ \\
\hline Economies of scale & o & $\bullet$ & ○ & ○ & $\sigma^{f}$ \\
\hline Production integration & $\bullet$ & o & $\bullet$ & • & $\bullet^{\mathrm{g}}$ \\
\hline Lack of models to assess early decisions & $\bullet$ & $\bullet$ & o & $\bullet$ & o \\
\hline Acquiring competencies & $\bullet$ & ○ & $\bullet$ & o & $\bullet^{\mathrm{h}}$ \\
\hline Brand strategy & $\bullet$ & $\bullet$ & $\bullet$ & ○ & $\bullet^{\mathrm{i}}$ \\
\hline Process variety management & $\circ$ & ○ & $\bullet$ & ○ & $\mathrm{D}^{\mathrm{j}}$ \\
\hline Product variety management & ० & ० & ○ & ○ & $\mathrm{Q}^{\mathrm{j}}$ \\
\hline Change propagation & ○ & ० & ○ & ○ & $\bullet^{\mathrm{k}}$ \\
\hline Verification complexity & o & o & o & o & $\bullet^{1}$ \\
\hline
\end{tabular}

- Present, o Not discussed, ㅁ Another sector

${ }^{\mathrm{a}}$ (Harmel et al., 2006), ${ }^{\mathrm{b}}$ (Parslov and Mortensen, 2015), ${ }^{\mathrm{c}}$ (Clark and Paolucci, 2001), ${ }^{\mathrm{d}}$ (Coronado

Mondragon and Coronado Mondragon, 2018), ${ }^{\mathrm{e}}$ (Richter et al., 2016), ${ }^{\mathrm{f}}$ (Fixson, 2006), ${ }^{\mathrm{g}}$ (Michaelis and Johannesson, 2011), ${ }^{\mathrm{h}}$ (Batchelor, 2006), ${ }^{\mathrm{i}}$ (Lundbäck, 2002), ${ }^{\mathrm{j}}$ (Daaboul et al., 2011), ${ }^{\mathrm{k}}$ (Clarkson et al., 2004), ${ }^{1}$ (Scheidemann, 2006)

\section{Discussion}

In the present work, we investigated what are the challenges encountered when introducing a new technology into a product derived from a platform. Our goal was to categorize the findings from industrial use cases in conjunction with previous findings from the literature, and to better understand the connection to the expectations from practitioners.

A way of assessing the impact decisions regarding the flexibility of a product platform on the lifetime value that the platform delivers is to consider the flexibility (and associated concepts like scalability, etc.), as a core feature of any design being considered and analyse their contribution to all considered scenarios, including in risk analyses and considering any decision as a trade-off that includes them. It has been shown that embedding flexibility in the elements of an automotive platform can lower switching costs when challenged by varying demand, but the use case was based on traditional mechanical elements, missing the relations between non-neighbouring components.

We envision a situation "to be" where models are made available to the decision makers as soon as possible, instead of the current "as is" state of having the models developed late (if at all) during the development process. This would enable quicker, proactive decisions, instead of the usually slow and reactive current ways of working, and lead to also quicker and more optimal changes being introduced in the design of product platforms. Further areas of study are the relation between the product platform 
structure and mitigation strategies against the disruption caused by new technology integration, modelling of interfaces dynamically and at different levels during the development process, and determination of what information to highlight when changes happen, to help the decision-makers.

\section{Conclusion}

We investigated the challenges found in the integration of new technologies into product platforms. Our findings highlight a normative gap in the current automotive literature on how to approach this process and overcome some of the current challenges, such as the early availability of value models to assess for example the impact of flexibility and other 'ilities' in the lifecycle value of product platforms. Providing the development teams model-based tools and methods can support the decisions regarding trade-offs between platform changes and platform flexibility. The methods available in the literature are not all well-known in industry, and in addition, there is little reported in literature on the assessment of trade-offs between the compliance to existing product and process platform, and the user utility/value offered by introducing new technologies.

Our vision for the future of these processes is to support decision makers with a model-assisted methodology, that mitigates the consequences of the current challenges. The valuable feature of the methodology will be the translation of the interfaces between disciplines from the domain level up to a decision-making level by means of the functions required by the components, enabling the assessment of the platform flexibility.

\section{Acknowledgement}

The funding for this work was provided by the VISP project, co-funded by the Swedish Governmental Agency for Innovation Systems (VINNOVA), Volvo Cars Group (VCG) and Volvo Group Trucks Technology (VGTT).

\section{References}

Agard, B. and Bassetto, S. (2013), "Modular design of product families for quality and cost", International Journal of Production Research, Vol. 51 No. 6, pp. 1648-1667.

Batchelor, J. (2006), "Modularisation and the changing nature of automotive design capabilities", International Journal of Automotive Technology and Management, Vol. 6 No. 3, pp. 276-297.

Bauer, W. et al. (2015), "Determination of the Required Product Platform Flexibility from a Change Perspective", 2015 Annual IEEE Systems Conference (SysCon) Proceedings, IEEE, pp. 20-26.

Blessing, L.T.M. and Chakrabarti, A. (2009), DRM, a Design Research Methodology, DRM, a Design Research Methodology, Springer London, London, available at: https://doi.org/10.1007/978-1-84882-587-1

Van Den Broeke, M., Boute, R. and Samii, B. (2015), "Evaluation of product-platform decisions based on total supply chain costs", International Journal of Production Research, Taylor \& Francis, Vol. 53 No. 18, pp. 5545-5563.

Brusoni, S., Prencipe, A. and Pavitt, K. (2001), "Knowledge specialization, organizational coupling, and the boundaries of the firm: Why do firms know more than they make?", Administrative Science Quarterly, Vol. 46 No. 4, pp. 597-621.

Buganza, T. and Verganti, R. (2006), "Life-cycle flexibility: How to measure and improve the innovative capability in turbulent environments”, Journal of Product Innovation Management, Vol. 23 No. 5, pp. 393-407.

Clark, W.W. and Paolucci, E. (2001), "Commercial development of environmental technologies for the automotive industry towards a new model of technological innovation", International Journal of Environmental Technology and Management, Vol. 1 No. 4, pp. 363-383.

Clarkson, P.J., Simons, C. and Eckert, C. (2004), "Predicting Change Propagation in Complex Design", Journal of Mechanical Design, Vol. 126 No. 5, p. 788.

Coronado Mondragon, A.E. and Coronado Mondragon, C.E. (2018), "Managing complex, modular products: how technological uncertainty affects the role of systems integrators in the automotive supply chain", International Journal of Production Research, Taylor \& Francis, Vol. 56 No. 20, pp. 6628-6643.

Daaboul, J. et al. (2011), "Design for mass customization: Product variety vs. process variety", CIRP Annals Manufacturing Technology, Vol. 60 No. 1, pp. 169-174.

Du, X., Jiao, J. and Tseng, M.M. (2003a), "Modelling platform-based product configuration using programmed attributed graph grammars", Journal of Engineering Design, Vol. 14 No. 2, pp. 145-167.

Du, X., Tseng, M.M. and Jiao, J. (2003b), "Product Families for Mass Customization", In: Tseng, M.M. and Piller, F.T. (Eds.), The Customer Centric Enterprise, Springer Verlag, Berlin, Heidelberg, pp. 123-161. 
Eklund, U. et al. (2005), "Experience of introducing reference architectures in the development of automotive electronic systems", SEAS 2005 - Proceedings of the 2nd International Workshop on Software Engineering for Automotive Systems. available at: https://doi.org/10.1145/1083190.1083195

Eliasson, U. et al. (2015), "Architecting in the Automotive Domain: Descriptive vs Prescriptive Architecture", Proceedings - 12th Working IEEE/IFIP Conference on Software Architecture, WICSA 2015, IEEE, pp. 115-118.

Erens, F.J. and Wortman, H.C. (1996), "Generic product modeling for mass customization", Implementation Road Map 1996, No. January, pp. 1-23.

Erixon, G. (1998), Modular Function Deployment, Institutionen för produktionssystem, available at: http://swepub.kb.se/bib/swepub:oai:DiVA.org:kth-2619?tab2=abs\&language=en

Farrell, R.S. and Simpson, T.W. (2010), "Improving cost effectiveness in an existing product line using component product platforms", International Journal of Production Research, Vol. 48 No. 11, pp. 3299-3317.

Fixson, S.K. (2006), “A Roadmap for Product Architecture Costing”, In: Simpson, T.W., Siddique, Z. and Jiao, J.R. (Eds.), Product Platform and Product Family Design: Methods and Applications, Springer US, New York, NY, pp. 305-334.

Förg, A. et al. (2014), "Enabling modularisation potentials by standardized vehicle layouts", Proceedings of NordDesign 2014 Conference, NordDesign 2014, pp. 754-764.

Fulcoly, D.O., Ross, A.M. and Rhodes, D.H. (2012), "Evaluating system change options and timing using the epoch syncopation framework", Procedia Computer Science, Vol. 8, pp. 22-30.

Hackl, J. and Krause, D. (2017), "Towards an impact model of modular product structures", Proceedings of the International Conference on Engineering Design, ICED, Vol. 3 No. DS87-3, pp. 151-160.

Halman, J.I.M., Hofer, A.P. and Vuuren, W.V. (2003), "Platform-Driven Development of Product Families: Linking Theory with Practice", The Journal of Product Innovation Management, Vol. 20 No. 2, pp. 149-162.

Harmel, G., Bonjour, E. and Dulmet, M. (2006), "A method to manage the co-evolution of Product an Organization architectures", The Proceedings of the Multiconference on Computational Engineering in Systems Applications, IEEE, Vol. 21, pp. 1207-1214.

Haubelt, C., Richter, K. and Ernst, R. (2002), "System Design for Flexibility", Proceedings of Design, Automation and Test in Europe (DATE'02), Paris, France, pp. 854-861.

Hölttä-Otto, K. (2005), Modular Product Platform Design, Vol. 18, available at: https://doi.org/10.1016/S14488272(05)80018-5

Isaksson, O. et al. (2013), "Value-Driven Design - A methodology to Link Expectations to Technical Requirements in the Extended Enterprise", INCOSE International Symposium, Vol. 23 No. 1, pp. 803-819.

Jana, P., Graves, S.C. and Grunow, M. (2018), "Balancing Benefits and Flexibility Losses in Platform Planning", SSRN Electronic Journal, pp. 1-38.

Jianxin Jiao, T., Qinhai Ma, M.M. and Zou, Y. (2000), "Generic Bill-of-Materials-and-Operations for HighVariety Production Management”, Concurrent Engineering, Vol. 8 No. 4, pp. 297-321.

Jiao, J., Simpson, T.W. and Siddique, Z. (2007), "Product family design and platform-based product development: A state-of-the-art review", Journal of Intelligent Manufacturing, Vol. 18 No. 1, pp. 5-29.

Jiao, J. and Tseng, M.M. (1999), "Methodology of developing product family architecture for mass customization", Journal of Intelligent Manufacturing, Vol. 10 No. 1, pp. 3-20.

Johannesson, H. et al. (2017), "Development of product platforms: Theory and methodology", Concurrent Engineering Research and Applications, Vol. 25 No. 3, pp. 195-211.

Kim, S. and Moon, S.K. (2017), "Sustainable platform identification for product family design", Journal of Cleaner Production, Elsevier Ltd, Vol. 143, pp. 567-581.

Kreimeyer, M. and Lindemann, U. (2011), Complexity Metrics in Engineering Design, Journal of Chemical Information and Modeling, Springer Berlin Heidelberg, Berlin, Heidelberg, available at: https://doi.org/ 10.1007/978-3-642-20963-5

Levandowski, C., Michaelis, M.T. and Johannesson, H. (2014), "Set-based development using an integrated product and manufacturing system platform", Concurrent Engineering Research and Applications, Vol. 22 No. 3, pp. 234-252.

Lundbäck, M. (2002), "Cross-brand product platforms: a product development perspective on acquisitions in the automotive industry”, International Journal of Automotive Technology and Management, Vol. 2 No. 3-4, pp. 261-279.

Meyer, M.H. and Lehnerd, A.P. (1997), "The power of product platforms: building value and cost leadership", 1997, New York, NY, Vol. 10020, p. 39.

Michaelis, M.T. and Johannesson, H. (2011), "Platform approaches in manufacturing - Considering integration with product platforms", Proceedings of the ASME Design Engineering Technical Conference, Vol. 9 No. February 2015, pp. 1115-1124.

Mintzberg, H., Raisinghani, D. and Theoret, A. (1976), "The Structure of 'Unstructured' Decision Processes", Administrative Science Quarterly, Vol. 21 No. 2, p. 246. 
Mirshekarian, S. (2015), "Enhanced Time-Expanded Decision Network: The Original TDN and More", Systems Engineering, Vol. 18 No. 4, pp. 415-429.

Oh, K. et al. (2019), "A Framework for Development Architecture for Modular Products: Cross-Domain Variety Management Perspective", Proceedings of the Design Society: International Conference on Engineering Design, Vol. 1 No. 1, pp. 2921-2930.

Otto, K. et al. (2016), "Global Views on Modular Design Research: Linking Alternative Methods to Support Modular Product Family Concept Development”, Journal of Mechanical Design, ASME International, Vol. 138 No. 7, p. 071101.

Parslov, J.F. and Mortensen, N.H. (2015), "Interface definitions in literature: A reality check", Concurrent Engineering Research and Applications, Vol. 23 No. 3, pp. 183-198.

Patel, P. and Pavitt, K. (1997), "The technological competencies of the world's largest firms: Complex and pathdependent, but not much variety", Research Policy, Vol. 26 No. 2, pp. 141-156.

Pelliccione, P. et al. (2017), “Automotive Architecture Framework: The experience of Volvo Cars", Journal of Systems Architecture, Vol. 77, pp. 83-100.

Richter, T., Inkermann, D. and Vietor, T. (2016), “A framework for integrated product architecture design", Proceedings of NordDesign", NordDesign, Vol. 2016 No. 1.

Ross, A.M. et al. (2004), "Multi-Attribute Tradespace Exploration as Front End for Effective Space System Design", Journal of Spacecraft and Rockets, Vol. 41 No. 1, pp. 20-28.

Scheidemann, K.D. (2006), "Optimizing the selection of representative configurations in verification of evolving product lines of distributed embedded systems", Proceedings - 10th International Software Product Line Conference, SPLC 2006, pp. 75-84.

Schrieverhoff, P. et al. (2012), "Evaluation of architecture options in systems engineering", Proceedings of International Design Conference, DESIGN, Vol. DS 70, pp. 1791-1802.

Schroeder, J. et al. (2016), "Design and evaluation of a customizable multi-domain reference architecture on top of product lines of self-driving heavy vehicles - An industrial case study", Lecture Notes in Informatics (LNI), Proceedings - Series of the Gesellschaft Fur Informatik (GI), IEEE, Vol. P252, pp. 77-78.

Seepersad, C.C., Hernandez, G. and Allen, J.K. (2000), A Quantitative Approach to Determining Product Platform Extent", ASME Advances in Design Automation Conference, No. January 2000.

Silver, M.R. and de Weck, O.L. (2007), "Time-expanded decision networks: A framework for designing evolvable complex systems", Systems Engineering, Vol. 10 No. 2, pp. 167-188.

Stocker, J. et al. (2016), "Development of market-oriented architectural standards by means of standardized vehicle layouts", Proceedings of NordDesign, NordDesign 2016, Vol. 1, available at https://www. designsociety.org/publication/39311/Development+of+market-oriented+architectural+standards+by+ means+of+standardized+vehicle+layouts.

Suh, E.S., De Weck, O.L. and Chang, D. (2007), "Flexible product platforms: Framework and case study", Research in Engineering Design, Vol. 18 No. 2, pp. 67-89.

Templier, M. and Paré, G. (2015), "A Framework for Guiding and Evaluating Literature Reviews", Communications of the Association for Information Systems, Vol. 37, available at: https://doi.org/10.17705/ 1CAIS.03706.

Thyssen, J., Israelsen, P. and Jørgensen, B. (2006), "Activity-based costing as a method for assessing the economics of modularization-A case study and beyond", International Journal of Production Economics, Vol. 103 No. 1, pp. 252-270.

Ulrich, K.T. and Eppinger, S.D. (2012), Product Design and Development, Fifth-In, McGraw-Hill, Singapore. available at: https://www.pdd-resources.net/

Upton, D.M. (1994), “The Management of Manufacturing Flexibility”, California Management Review, Vol. 36 No. 2, pp. 72-89.

De Weck, O.L., Ross, A.M. and Rhodes, D.H. (2012), "Investigating Relationships and Semantic Sets amongst System Lifecycle Properties (Ilities)", Third International Engineering Systems Symposium CESUN 2012, Delft University of Technology, 18-20 June 2012, No. June, pp. 18-20.

De Weck, O.L., Suh, E.S. and Chang, D. (2003), "Product family and platform portfolio optimization", Proceedings of the ASME Design Engineering Technical Conference, Vol. 2 A, pp. 175-185.

Woolley, M., Scanlan, J. and Eveson, W. (2001), "Optimising the Development of a Medical Device Using Formal Engineering Design Techniques and the CODA-System", Proceedings in the 7th International Conference on Concurrent Enterprising, pp. 367-376. 